\title{
GINA: making it safe to know what's in your genes
}

resident George W. Bush recently signed into law the Genetic Information Nondiscrimination Act (GINA), a bill that outlaws employers and health insurance companies from discriminating against individuals based on the results of genetic tests.

Specifically, the legislation bans health insurance companies from both asking for and using genetic information to make decisions about coverage and to set premiums. Health insurance companies are also barred from raising premiums for a group because one or more of its members have a genetic predisposition to an illness. The bill also bars employers, unions, and employment agencies from requesting to see or using genetic information for the purposes of hiring, promoting, assigning, or firing an individual.

Legislation to ban discrimination against individuals based on their genetics has been in the works for many years - it was first proposed 13 years ago in the House of Representatives by Rep. Louise Slaughter (D-New York), who also co-sponsored the bill now signed into law. The Senate even unanimously passed similar bills in 2003 and

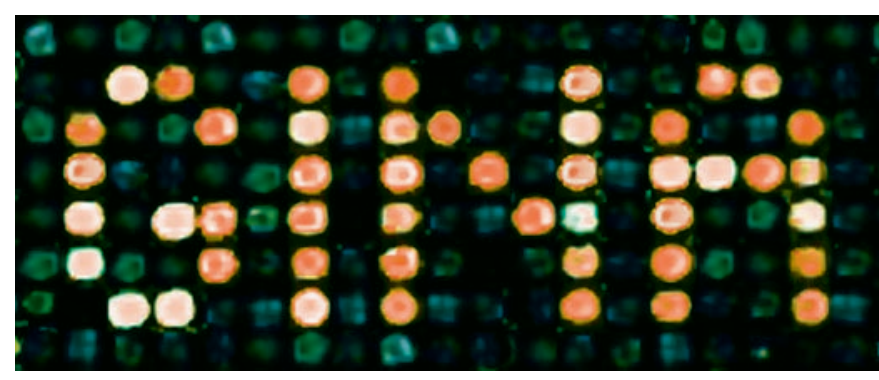

GINA is a new law that prevents employers and health insurance companies from discriminating against individuals based on the results of genetic tests. illness in the future is the most relevant to the new legislation, as there are now more than 1,500 such genetic tests, including tests that indicate susceptibility to breast cancer, Alzheimer disease, and heart disease. According to Francis Collins, director of the National Human Genome Research Institute, "Many people have been unwilling to participate in medical research or be tested clinically, even when at substantial risk of serious disease, because of fears their genetic information might be used against them." He hopes that GINA will change this, telling the JCI, "This law is a great gift to all Americans because it provides the protections we need to freely
BRCA1 and BRCA2 mutations associated with an increased risk of breast and ovarian cancer can be offered preventive measures such as prophylactic mastectomy and surgical removal of ovaries. However, the situation is far more complex for most common conditions, such as diabetes and heart disease, in which many genes and environmental factors interact to establish an individual's risk of disease. Regardless, Collins is optimistic: "The hope is that sometime within the next few years, health care providers will be able to scan each of our genomes to identify the most significant genetic variations that predispose each of us to certain diseases. Not only should this offer better opportunities for diagnosis and prevention, it should lead to the development of more individualized strategies for treating or managing the disease if it does occur." However, this optimism is not universal; Ostrer told the JCI that he does not expect genome-wide genetic testing to routinely enter clinical practice for 10 years or more.

Despite general agreement among renowned physicianscientists that routine clinical use of genetic testing is at least duced or passed by the House of Representatives. Thus, many researchers agree with Harry Ostrer, director of the Human Genetics Program in the Department of Pediatrics at New York University Langone Medical Center, who told the JCI, "GINA has been a long time coming."

The term genetic testing covers a wide array of techniques, including those used to determine paternity. However, most provide clinically relevant information and are used to confirm a suspected diagnosis, to predict susceptibility to an illness, to identify individuals who carry a specific genetic mutation but remain unaffected themselves, or to predict how an individual is likely to respond to a certain therapy. Genetic tests are also used to screen fetuses, newborns, and embryos used in in vitro fertilization for genetic defects.

Genetic testing to predict whether an individual is susceptible to developing an participate in genomic medicine without fear of discrimination in employment and health insurance. Each of us has dozens of genetic variations that may put us at risk for disease, so we all have reason to be concerned about the possible misuse of our genetic information."

The idea behind many genetic tests is to provide more "personalized" medical care. But, as Collins noted, "How much a genetic test will benefit an individual today in terms of medical intervention varies widely depending upon the disease." He provided two examples in which genetic testing can currently be of benefit: in the case of hereditary nonpolyposis colorectal cancer, genetic tests can pinpoint those people at high risk for the disease such that they receive early screening and removal of precancerous polyps, and in the case of breast cancer, women identified as carrying the several years in the making, the number of for-profit companies that offer direct-toconsumer genetic testing has increased dramatically in recent years. Ostrer believes this development to be premature, because some of the genetic tests offered - in particular, those providing information about an individual's risk of multigenic disorders with an environmental component, such as diabetes and heart disease - have neither been fully validated nor proven to be of clinical value. Although GINA is a step forward, he told the JCI, enforcement by the FDA and Federal Trade Commission of existing statutes and regulations is needed to ensure that genetic tests are themselves adequately regulated, so that only tests of proven clinical value are offered to patients and consumers.

\section{Karen Honey}

